\title{
Vaporisation of group 13 elements from basaltic melts by Knudsen Effusion Mass Spectrometry
}

\author{
LUKAS BISCHOF ${ }^{1}$, PAOLO A. SOSSI ${ }^{1}$, DMITRY \\ SERGEEV $^{2}$, MICHAEL MÜLLER ${ }^{2}$ AND MAX W. \\ SCHMIDT $^{1}$
}

${ }^{1}$ ETH Zürich

${ }^{2}$ Forschungszentrum Jülich

Presenting Author: lukas.bischof@erdw.ethz.ch

The composition of Bulk Silicate Earth provides the reference against which models of Earth's accretion and differentiation can be assessed. Lithophile volatile elements (e.g. alkalis and $\mathrm{Zn}$ ) in the BSE decline in abundance as a function of their $50 \%$ nebular condensation temperatures. However, the moderately volatile elements $\mathrm{Ga}$ and In, in spite of being siderophile, lie on or above the trend defined by the lithophile volatile elements. This observation implies either the late accretion of a CI-like component to the Earth, resulting in a 'plateau' of moderately volatile elements, or that conditions during volatile depletion diverged from those of the canonical solar nebula, leading to different element volatilities, e.g. by impact events.

To characterise the vaporisation behaviour of $\mathrm{Ga}$, In and $\mathrm{Tl}$ from silicate melts, Knudsen Effusion Mass Spectrometry was applied to determine the identity and vapour pressures of the evaporating species. Powders of pure $\mathrm{Ga}_{2} \mathrm{O}_{3}(\mathrm{~s}), \mathrm{In}_{2} \mathrm{O}_{3}(\mathrm{~s})$ and anorthite-diopside eutectic glasses doped with $\sim 1000$ and $\sim 10,000 \mathrm{ppm}$ of $\mathrm{Ga}$ and In were placed in iridium Knudsen cells and heated by a tungsten wire furnace up to $1750 \mathrm{~K}$, producing a vapour inside the cell in equilibrium with the liquid. A small fraction of the vapour effuses out of the orifice to form a molecular beam that was subsequently ionised at $60 \mathrm{eV}$, with resulting intensities measured on a Finnigan MAT 271 mass spectrometer.

We detected the ions $\mathrm{M}^{+}, \mathrm{M}^{2+}, \mathrm{M}^{3+}, \mathrm{M}_{2}^{+}, \mathrm{MO}^{+}$and $\mathrm{M}_{2} \mathrm{O}^{+}$(where $\mathrm{M}=\mathrm{Ga}$ or In) above the pure oxides $\mathrm{Ga}_{2} \mathrm{O}_{3}$ and $\mathrm{In}_{2} \mathrm{O}_{3}$. Tl proved to be too volatile to obtain useful signals at high temperatures. Following corrections for ionisation cross sections and ion fragmentation, we find that partial pressures decline in the order $p \mathrm{M}_{2} \mathrm{O}>p \mathrm{M}^{0}>>p \mathrm{MO}$, in agreement with previous work. The ions $\mathrm{M}^{+}, \mathrm{MO}^{+}$and $\mathrm{M}_{2} \mathrm{O}^{+}$were observed for both $\mathrm{Ga}$ and $\mathrm{In}$ above the silicate melt, however, $p\left(\mathrm{M}^{0}\right) / p\left(\mathrm{M}_{2} \mathrm{O}\right)$ were higher than for pure oxides. We show that this behaviour reflects the lower activities of $\mathrm{GaO}_{1.5}$ and $\mathrm{InO}_{1.5}$ in the liquid, indicating that $\mathrm{Ga}$ and In are relatively less volatile during evaporation of silicate melts than predicted from their nebular condensation temperatures. 